\title{
Inhaled nitric oxide in hypoxaemic newborns who are candidates for extracorporeal life support
}

\author{
P. Biban, D. Trevisanuto, A. Pettenazzo, P. Ferrarese, E. Baraldi, F. Zacchello
}

Inhaled nitric oxide in hypoxaemic newborns who are candidates for extracorporeal life support. P. Biban, D. Trevisanuto, A. Pettenazzo, P. Ferrarese, E. Baraldi, F. Zacchello. CERS Journals Ltd 1998.

ABSTRACT: The aim of this study was to evaluate the effect of inhaled nitric oxide (NO) in newborns with acute hypoxaemic respiratory failure and the impact of this NO therapy on survival and the need for extracorporeal membrane oxygenation (ECMO)

A cohort of newborns with a gestational age of $\geq 34$ weeks and an oxygenation in$\operatorname{dex}(\mathrm{OI})>25$ were prospectively evaluated. Patients were given NO at an initial dose of 10 parts per million (ppm). Oxygenation parameters were evaluated prior and during NO inhalation. From January 1994 to December 1996, 20 infants were en-rolled in the study. Based upon their outcome, patients were divided into two groups: survivors with no need for ECMO, group $A(n=8)$ and survivors requiring ECMO or nonsurvivors, group B $(\mathbf{n}=12)$.

All infants approached or met ECMO criteria before NO inhalation. Eight patients $(40 \%)$ were successfully managed with $\mathrm{NO}$ and conventional treatment (group A). Newborns in this group showed a rapid and sustained improvement of systemic oxygenation during $\mathrm{NO}$ inhalation. Mean arterial oxygen tension $\left(\mathrm{Pa}_{\mathrm{a}} \mathrm{O}_{2}\right)$ increased significantly from $4.5 \mathrm{kPa}(34 \mathrm{mmHg})(95 \%$ confidence interval $(95 \% \mathrm{CI}) 1.9-7.1$ kPa (14.4-53.7 mmHg)) to $10.1 \mathrm{kPa}(75.7 \mathrm{mmHg})(95 \%$ CI 6.5-13.6 kPa (49.1-102.3 $\mathrm{mmHg})$ ) after $1 \mathrm{~h}$ and was $9.0 \mathrm{kPa}(67.7 \mathrm{mmHg})(95 \% \mathrm{CI}$ 7.1-11.0 $\mathrm{kPa}(53.1-82.4$ $\mathrm{mmHg}$ ) at $24 \mathrm{~h}$. Conversely, none of the oxygenation parameters improved in the 12 patients who ultimately required ECMO or died (group B).

The results indicate that inhaled nitric oxide can improve systemic oxygenation in newborns with acute respiratory failure and may reduce the need for extracorporeal membrane oxygenation support in candidates. Lack of a rapid response to nitric oxide may be an early predictor of unfavourable short-term outcome, prompting a move towards alternative treatments.

Eur Respir J 1998; 11: 371-376.
Dept of Paediatrics, School of Medicine, University of Padova, Padova, Italy.

Correspondence: P. Biban

Patologia Neonatale

Divisione di Pediatria

University of Verona

Piazzale Stefani n.1

Ospedale Borgo Trento

37126 - Verona

Italy

Fax: 39458073373

Keywords: Extracorporeal membrane oxygenation

inhaled nitric oxide

newborn

Received: May 221997

Accepted after revision September 301997
Term and preterm newborns suffering from severe hypoxaemic respiratory failure, either due to persistent pulmonary hypertension (PPHN) or respiratory distress syndrome (RDS), still account for a relatively high morbidity and mortality $[1,2]$. Several treatments have been attempted in these patients, such as exogenous surfactant replacement, i.v. vasodilators such as tolazoline and prostacyclins, inhaled prostacyclins, magnesium sulphate, highfrequency ventilation and liquid ventilation, although rarely has their efficacy been confirmed by controlled studies [3-6]. Extracorporeal membrane oxygenation (ECMO) constitutes a valid therapeutic option in neonates with refractory hypoxaemia $[7,8]$, as recently confirmed by the UK ECMO collaborative trial [9]. However, ECMO remains a complex and expensive technique that requires systemic anticoagulation and cannulation of major vessels. Inhaled nitric oxide (NO) has been shown to be a promising novel treatment in hypoxaemic newborns with severe PPHN, either idiopathic or secondary to various cardiopulmonary diseases. In using this therapy several authors have observed a marked improvement of oxygenation in most patients and a decline of ECMO cases [10-12]. It is still unclear, however, why in some patients gas exchange during NO therapy is not improved and whether, in cases of positive response, a rapid improvement of oxygenation is necessarily associated with a favourable outcome. The objectives of this study were: 1) to assess the acute physiological effect of inhaled NO on systemic oxygenation in newborns with acute respiratory failure approaching ECMO criteria; and 2) to evaluate whether survival without ECMO support was correlated to an acute and sustained response to inhaled NO and, conversely, whether death or need for ECMO could be anticipated by a poor or absent response.

\section{Methods}

This study was approved by the Ethics and Scientific Review Board at the Department of Paediatrics, University of Padova. Informed parental consent was obtained prior to initiation of NO therapy. All newborns admitted at 
the Neonatal Intensive Care Unit (NICU) of the Institution were considered as possible candidates for this study. Patients with congenital heart defects were excluded. Infants had to be mechanically ventilated, with an inspiratory oxygen fraction $\left(F \mathrm{I}, \mathrm{O}_{2}\right)$ of 1.0. Entry criterion was an oxygenation index $(\mathrm{OI})>25$, despite optimization of conventional support, i.e. haemodynamic support with inotropes and/or fluids, alkalinization by hyperventilation or buffer infusion, sedation and/or muscle relaxation and one or more doses of exogenous surfactant (Curosurf®; Chiesi, Parma, Italy). Vital parameters were continuously monitored throughout the study period. For the 2-D echocardiographic and Doppler studies, CFM 700 (Vingmed, Horten, Norway) mechanical equipment was used. Echocardiographic evaluations were performed before and during the first hour of NO inhalation, in order to identify signs of extrapulmonary right-to-left shunting at the ductal and/or the foramen ovale level and to assess the effect of NO on pulmonary vascular resistance.

\section{NO delivery and monitoring}

NO was provided in 20 L cylinders (Air Liquide Sanità, Milan, Italy), at a certified concentration of 500-520 parts per million (ppm) of NO in nitrogen, with a nitrogen dioxide $\left(\mathrm{NO}_{2}\right)$ content $<1 \%$. During assisted ventilation, performed either with a conventional time cycled, pressure limited, continuous flow ventilator (Babylog 8000; Sensor Medics, Dräger, Lübeck, Germany) or with a highfrequency oscillatory ventilator (3100A; Yorba Linda, CA, USA), the NO mixture was administered in the inspiratory limb of the circuit by means of a low-scale flow regulator, at about $40 \mathrm{~cm}$ from the $\mathrm{Y}$-connector. We maintained a ventilator gas flow rate at $\geq 10 \mathrm{~L} \cdot \mathrm{min}^{-1}$, in order to minimize the contact time between $\mathrm{NO}$ and oxygen within the circuit, thus reducing the formation of higher nitrogen oxides. $\mathrm{NO}$ and $\mathrm{NO}_{2}$ concentrations were continuously monitored, either with a chemiluminescence analyser (CLD 700 AL med; ECO Physics, Dürnten, Switzerland) or by electrochemical sensors (Triple plus, Crowcon, UK; Noxide M3 AIME, Dräger, Corsico-Milan, Italy). The gas mixture was sampled from the inspiratory limb of a modified ventilator circuit, just before the endotracheal tube. Exhaust gases were scavenged. Methaemoglobin (metHb) levels were measured every $8-12 \mathrm{~h}$ in the early phase of treatment, and then twice a day. NO concentration had to be reduced or ultimately stopped in case of $\mathrm{NO}_{2}$ levels $>2$ ppm or metHb values persistently $>5 \%$.

\section{Study protocol}

Inhalation of NO was started at an initial concentration of $10 \mathrm{ppm}$. When systemic oxygenation did not improve after the first few minutes of NO inhalation, the caring physician could increase the initial NO dose, by steps of $10 \mathrm{ppm}$ up to a maximum of $40 \mathrm{ppm}$. Conversely, when there was a marked improvement of oxygenation during the first hours of $\mathrm{NO}$ inhalation, the $\mathrm{FI}_{1} \mathrm{O}_{2}$ and/or the peak pressure of the ventilator could be lowered in order to limit further damage to the lungs. The arterial oxygen pressure $\left(\mathrm{Pa}_{\mathrm{a}} \mathrm{O}_{2}\right)$, OI and alveolar-arterial pressure difference for oxygen $\left(P \mathrm{~A}-\mathrm{a}, \mathrm{O}_{2}\right)$ were evaluated immediately prior to NO inhalation, and after 1, 3, 6, and $24 \mathrm{~h}$ of therapy. OI and $\mathrm{PA}-\mathrm{a}, \mathrm{O}_{2}$ were calculated with the following formulas:

$\mathrm{OI}=$ mean airway pressure $\times F \mathrm{I}_{1} \mathrm{O}_{2} \times 100 /$ postductal $P \mathrm{a}, \mathrm{O}_{2}$ $P \mathrm{~A}-\mathrm{a}, \mathrm{O}_{2}=(760-47) \times F \mathrm{I}, \mathrm{O}_{2}-P \mathrm{a}, \mathrm{O}_{2}-P \mathrm{a}, \mathrm{CO}_{2}$

where 760 is the barometric pressure $(\mathrm{mmHg}) ; 47$ is the partial pressure of water vapour $(\mathrm{mmHg})$; and $P \mathrm{a}, \mathrm{CO}_{2}$ is the arterial carbon dioxide tension. Newborns with birth weight $>2,000 \mathrm{~kg}$ and gestational age $\geq 34$ weeks, with OI $\geq 40$ for $>3 \mathrm{~h}$ and/or $P \mathrm{~A}-\mathrm{a}, \mathrm{O}_{2}>610 \mathrm{mmHg}$ for more than $8 \mathrm{~h}$, were considered candidates for ECMO [8]. ECMO was initiated in cases of values persistently beyond such limits, despite NO inhalation. In the study centre venovenous or veno-arterial ECMO by means of a roller occlusive pump (Jostra ${ }^{\circledR}$, Hirrlingen, Germany) and two types of silicone membrane oxygenator (Avecor®, Plymouth MN, USA; Jostra $\left.{ }^{\circledR}\right)$ were provided.

According to survival and the use of ECMO, patients were divided into two groups: survivors not requiring ECMO (group A) and survivors requiring ECMO treatment or nonsurvivors (group B).

\section{Statistical analysis}

Demographic data, duration and doses of NO, and metHb are expressed as median and range, while gas exchange parameters are expressed as mean and $95 \%$ confidence intervals $(95 \% \mathrm{CI})$ unless specifically stated otherwise.

Because data were not normally distributed, nonparametric statistical analyses were used for within-group (Wilcoxon Signed-Rank test) and between group (MannWhitney U-test) comparisons. The rate of right-to-left shunting reversal in the two groups was compared with the Fisher exact test (two-tailed). A p-value $<0.05$ was considered statistically significant. Data elaboration was performed by using a specific software (Statistica, OStatSoft Inc., Tulsa, OK, USA).

\section{Results}

Between January 1994 and December 1996, 20 infants with severe hypoxaemic respiratory failure were enrolled in the study. Demographic and outcome data for all patients are shown in table 1 . In the whole group, mean $\mathrm{Pa}_{\mathrm{a}} \mathrm{O}_{2}$ before NO inhalation was $4.5 \mathrm{kPa}(33.7 \mathrm{mmHg})(95 \% \mathrm{CI}$ $3.2-5.7 \mathrm{kPa}(24.2-43.1 \mathrm{mmHg})),{\mathrm{PA}-\mathrm{a}, \mathrm{O}_{2}}_{2}$ was $83.0 \mathrm{kPa}$ $(623 \mathrm{mmHg})(95 \%$ CI $81.3-84.5 \mathrm{kPa}(611-635 \mathrm{mmHg}))$ and OI was 76.4 (95\% CI 58.6-94.2). The duration of NO inhalation was $33 \mathrm{~h}$ (range 6-331). Median initial and maximal NO doses were 10 and 30 ppm, respectively. In a few patients, due to their agonic conditions, the caring physician started with higher NO concentrations $(\leq 40$ ppm). Two unresponsive patients received a short NO trial at $80 \mathrm{ppm}$, with no benefit.

Eight patients survived without ECMO (group A), while 10 were treated with ECMO and two died before ECMO (group B). Patient characteristics in the two groups are shown in table 2. Except for the three infants with RDS and the six with congenital diaphragmatic 
Table 1. - Patient demographic and outcome data

\begin{tabular}{ccccccc}
\hline $\begin{array}{c}\text { Pt } \\
\text { No. }\end{array} \begin{array}{c}\text { Gestat. } \\
\text { age } \\
\text { weeks }\end{array}$ & $\begin{array}{c}\text { Birth } \\
\text { weight } \\
\text { kg }\end{array}$ & Diag. & $\begin{array}{c}\text { Surfact. } \\
\text { Pre-NO }\end{array}$ & $\begin{array}{c}\text { HFOV } \\
\text { Pre-NO }\end{array}$ & ECMO/Alive \\
\hline 1 & 38 & 3.03 & MAS & Y & N & N/Y \\
2 & 35 & 2.04 & RDS & Y & N & N/Y \\
3 & 40 & 3.50 & PIE & Y & N & Y/Y \\
4 & 34 & 2.53 & RDS & Y & N & N/Y \\
5 & 37 & 2.70 & CDH & Y & N & Y/N \\
6 & 39 & 2.97 & Sepsis & Y & N & N/Y \\
7 & 41 & 4.06 & Sepsis & Y & N & N/Y \\
8 & 38 & 3.49 & PPHN & Y & N & N/Y \\
9 & 40 & 2.81 & MAS & Y & N & N/Y \\
10 & 38 & 3.71 & CDH & Y & N & Y/N \\
11 & 37 & 2.81 & CDH & Y & N & Y/N \\
12 & 40 & 3.25 & Sepsis & Y & N & Y/Y \\
13 & 41 & 3.96 & MAS & Y & N & Y/Y \\
14 & 40 & 3.44 & PPHN & Y & N & Y/Y \\
15 & 36 & 2.35 & RDS & Y & N & N/Y \\
16 & 36 & 3.05 & Sepsis & Y & N & N/N \\
17 & 37 & 2.90 & PPHN & Y & N & Y/Y \\
18 & 40 & 3.55 & CDH & Y & Y & Y/N \\
19 & 34 & 2.21 & CDH & Y & Y & N/N \\
20 & 40 & 4.39 & CDH & Y & Y & Y/N \\
\hline
\end{tabular}

Pt: patient; Gestat.: gestational; Diag.: diagnosis; Surfact.: surfactant; HFOV: high-frequency oscillatory ventilation; ECMO: extracorporeal membrane oxygenation; NO: nitric oxide; MAS: meconium aspiration syndrome; N: No; Y: Yes; RDS: respiratory distress syndrome; PIE: pulmonary interstitial emphysema; $\mathrm{CDH}$ : congenital diaphragmatic hernia; PPHN: persistent pulmonary hypertension of the newborn.

hernia $(\mathrm{CDH})$ who belonged to group A and group B, respectively, the other diagnoses were unevenly distributed in the two groups. As far as the gestational age, birth weight, gender, inborn/outborn rate and Apgar scores were concerned the two groups were comparable. Three patients, all with $\mathrm{CDH}$, were given a trial with high-frequency oscillatory ventilation (HFOV) prior to NO inhalation. All six patients with CDH had confirmation of their hypoplastic lung condition at autopsy. The age of onset of NO treatment and the duration of $\mathrm{NO}$ inhalation was greater in group A than in group B, although this was not signifi-

Table 2. - Patient characteristics in the two groups

\begin{tabular}{|c|c|c|c|}
\hline & $\underset{(n=8)}{\text { Group A }}$ & $\begin{array}{c}\text { Group B } \\
(n=12)\end{array}$ & $\begin{array}{c}\text { Mann- } \\
\text { Whitney } \\
\text { U-test }\end{array}$ \\
\hline $\begin{array}{l}\text { Gestational age } \\
\text { weeks }\end{array}$ & $38(34-41)$ & $39(34-41)$ & $\mathrm{p}=0.64$ \\
\hline Birth weight $\mathrm{kg}$ & $2.9(2.0-4.0)$ & $3.3(2.2-4.4)$ & $\mathrm{p}=0.18$ \\
\hline Gender M/F & $5 / 3$ & $9 / 3$ & $\mathrm{p}=0.56$ \\
\hline Inborn/outborn & $2 / 6$ & $5 / 7$ & $\mathrm{p}=0.45$ \\
\hline $\begin{array}{l}\text { Apgar score at } \\
1 \mathrm{~min}\end{array}$ & $7(1-9)$ & $7(1-10)$ & $\mathrm{p}=0.65$ \\
\hline $\begin{array}{l}\text { Apgar score at } \\
5 \mathrm{~min}\end{array}$ & $9(3-10)$ & $7.5(2-10)$ & $\mathrm{p}=0.62$ \\
\hline $\begin{array}{l}P \mathrm{a}, \mathrm{O}_{2} \text { Pre-NO } \\
\mathrm{kPa}\end{array}$ & $4.5(1.9-0.8)$ & $4.4(2.9-6.0)$ & $\mathrm{p}=0.70$ \\
\hline $\begin{array}{l}P \mathrm{~A}-\mathrm{a}, \mathrm{O}_{2} \text { Pre-NO } \\
\mathrm{kPa}\end{array}$ & $82.1(78.5-85.5)$ & $83.4(82.0-85.1)$ & $\mathrm{p}=0.59$ \\
\hline OI Pre-NO & $80.5(43.9-117)$ & $73.7(51-96)$ & $\mathrm{p}=0.70$ \\
\hline
\end{tabular}

Values are presented as median with range in parenthesis except $P \mathrm{a}, \mathrm{O}_{2}, P \mathrm{~A}-\mathrm{a}, \mathrm{O}_{2}$ and $\mathrm{OI}$ which are presented as median with $95 \%$ confidence intervals in parenthesis. $\mathrm{Pa}_{\mathrm{a}} \mathrm{O}_{2}$ : arterial oxygen tension; NO: nitric oxide; $P_{\mathrm{A}-\mathrm{a}, \mathrm{O}_{2}}$ : alveolar-arterial pressure difference for oxygen; OI: oxygenation index. $1 \mathrm{kPa}=7.52 \mathrm{mmHg}$.
Table 3. - Characteristics during nitric oxide (NO) inhalation in the two groups

\begin{tabular}{|c|c|c|c|}
\hline & $\begin{array}{c}\text { Group A } \\
(\mathrm{n}=8)\end{array}$ & $\begin{array}{l}\text { Group B } \\
(\mathrm{n}=12)\end{array}$ & $\begin{array}{c}\text { Mann- } \\
\text { Whitney } \\
\text { U-test }\end{array}$ \\
\hline Age at NO onset $h$ & $45.5(2-117)$ & $19.5 \quad(1-336)$ & $\mathrm{p}=0.08$ \\
\hline $\begin{array}{l}\text { Length of NO } \\
\text { inhalation } h\end{array}$ & $87 \quad(15-127)$ & $(6-331)$ & $\mathrm{p}=0.10$ \\
\hline Initial NO dose ppm & $(10-15)$ & $12.5(10-40)$ & $p=0.24$ \\
\hline Peak NO dose ppm & $(10-40)$ & $33.5(20-80)$ & $\mathrm{p}<0.01$ \\
\hline Peak metHb \% & $2(0.1-5)$ & $1.8(0.8-2.8)$ & $\mathrm{p}=0.68$ \\
\hline
\end{tabular}

Values are expressed as median with range in parenthesis. metHb: methaemoglobin.

cantly different (table 3). Starting NO concentrations were similar in the two groups while the maximum NO concentrations were higher in group B. Peak metHb levels remained below $5 \%$ and were comparable in the two groups (table 3).

\section{Gas exchange}

In the whole group a marked improvement of systemic oxygenation during $\mathrm{NO}$ inhalation was observed. $\mathrm{Pa}_{\mathrm{a}} \mathrm{O}_{2}$ increased from a mean baseline value of $4.4 \mathrm{kPa}(33.2$ $\mathrm{mmHg}$ (95\% CI $3.4-5.4 \mathrm{kPa}(25.5-40.9 \mathrm{mmHg}))$ to 7.0 $\mathrm{kPa}(52.5 \mathrm{mmHg})(1.15-8.8 \mathrm{kPa}(38.7-66.3 \mathrm{mmHg}))$ at $1 \mathrm{~h}(\mathrm{p}=0.007)$, being $7.5 \mathrm{kPa}(56.4 \mathrm{mmHg})(6.2-8.8 \mathrm{kPa}$ $(46.8-66 \mathrm{mmHg}))$ at $24 \mathrm{~h}(\mathrm{p}=0.02) . P \mathrm{~A}-\mathrm{a}, \mathrm{O}_{2}$ and $\mathrm{OI}$ decreased significantly at $1 \mathrm{~h}$ inhalation and this effect was sustained at $24 \mathrm{~h}$ (fig. 1). When patients were retrospectively divided into group A and group B, and the effect of NO therapy compared, it was found that despite the fact that baseline $\mathrm{Pa}, \mathrm{O}_{2}, P \mathrm{~A}-\mathrm{a}, \mathrm{O}_{2}$ and $\mathrm{OI}$ were not significantly different between the two groups (table 2), there was a distinct effect on systemic oxygenation during NO inhalation. In fact, patients in group A presented a rapid and sustained response at $1,3,6$, and $24 \mathrm{~h}$ of NO inhalation, whilst none of the oxygenation parameters improved significantly in patients in group B throughout the study period (fig. 2).

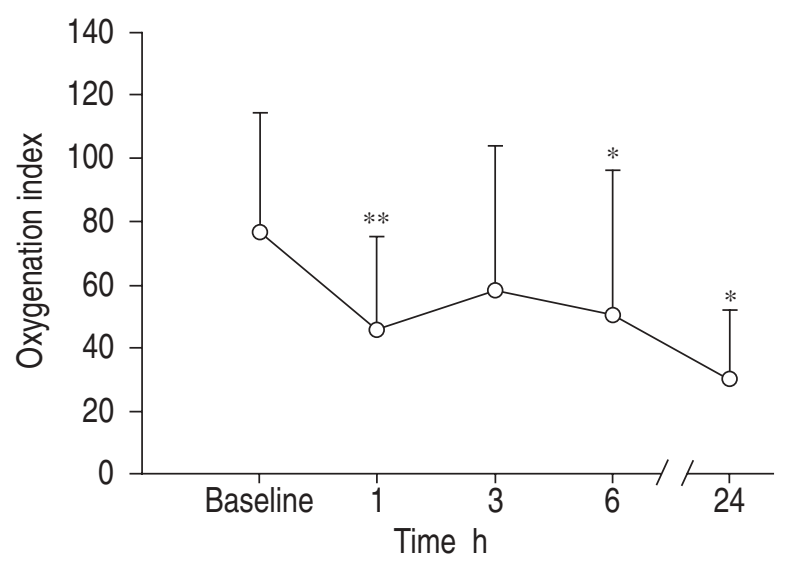

Fig. 1. - Changes in the oxygenation index (OI) during nitric oxide inhalation in 20 infants with severe hypoxaemic respiratory failure. An acute and sustained improvement of OI from $1 \mathrm{~h}$ of treatment is observed. Values are presented as mean \pm SD. Baseline: $n=20 ; 1 \mathrm{~h}: \mathrm{n}=20 ; 3 \mathrm{~h}$ : $\mathrm{n}=19 ; 6 \mathrm{~h}: \mathrm{n}=19 ; 24 \mathrm{~h}: \mathrm{n}=10 .{ }^{*}, * *: \mathrm{p}<0.05, \mathrm{p}<0.01$ compared to baseline using the Wilcoxon signed-rank test. 

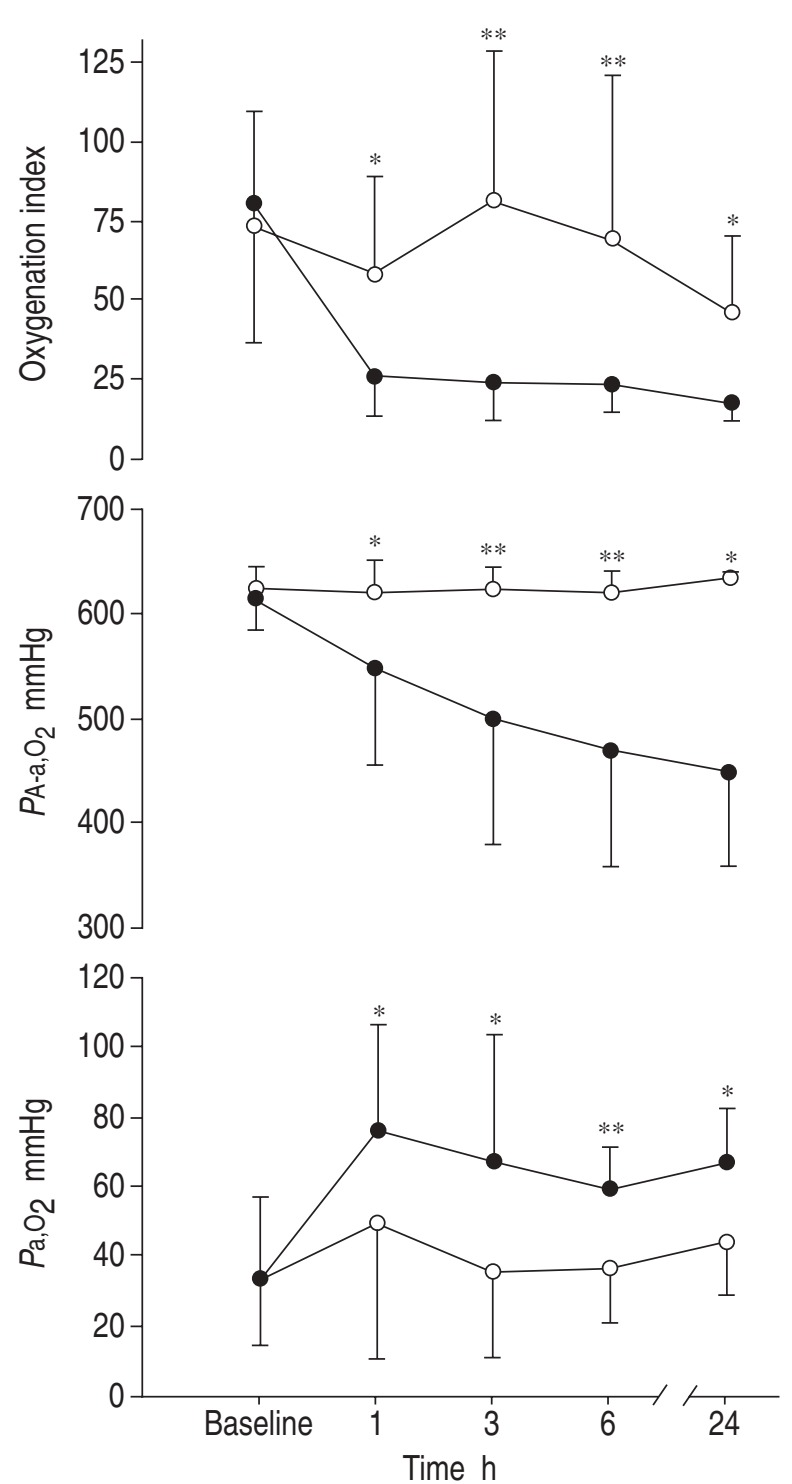

Fig. 2. - Changes in oxygenation parameters during nitric oxide inhalation in newborns who survived without extracorporeal membrane oxygenation (ECMO) (group $\mathrm{A}, \mathrm{n}=8$ ) and in newborns who survived after ECMO or died (group B, $n=12$ ). Despite comparable baseline values in the two groups, infants in group A showed a significant improvement in oxygenation from $1 \mathrm{~h}$ of NO treatment, while infants in group B showed no improvement in oxygenation throughout the study period. Data are presented as mean $\pm \mathrm{SD}$. $\bullet$ : group $\mathrm{A} ; \quad$ : group $\mathrm{B} ; \mathrm{PA}_{\mathrm{A}-\mathrm{a}, \mathrm{O}_{2}}$ : alveolar-arterial pressure difference for oxygen; $\mathrm{Pa}_{\mathrm{a}} \mathrm{O}_{2}$ : arterial oxygen tension. $* * *$ : $\mathrm{p}<0.05, \mathrm{p}<0.01$ for between group comparison using the Mann-Whitney U-test. $1 \mathrm{kPa}=7.52 \mathrm{mmHg}$.

All patients approached or fulfilled ECMO criteria: eight patients (40\%), (group A) improved with NO inhalation and did not require ECMO life support. Of 12 patients who deteriorated despite NO inhalation (group B), two died before ECMO treatment and 10 underwent ECMO. The five infants with $\mathrm{CDH}$ treated with ECMO ultimately died, while the other five nonCDH infants survived. Eventually, 13 out of 20 patients $(65 \%)$ were successfully discharged home.

A variable oxygenation response was observed in the various diagnostic categories. Among the six infants with $\mathrm{CDH}$, one showed a transient improvement of oxygenation while five failed to respond to NO inhalation. All six eventually died, five despite ECMO. Three infants with RDS showed a good response to NO and survived. In the remaining patients, five infants (two meconium aspirate syndrome (MAS), two sepsis, one PPHN) improved their oxygenation during NO and survived, while the other six (one MAS, two sepsis, two PPHN, one pulmonary interstitial emphysema (PIE)) did not show a sustained response to NO. In the latter subgroup, one patient died and five survived after ECMO.

Among the 15 patients evaluated by 2-D echocardiographic and Doppler studies before and during NO inhalation, 13 showed signs of extrapulmonary right-to-left shunting (seven in group A, six in group B). Seven patients $(100 \%)$ in group A had a reversal of shunting within $1 \mathrm{~h}$ of NO therapy, as opposed to two (33.3\%) in group B $(\mathrm{p}=0.02)$. Of the two patients who had no signs of rightto-left shunting, one died and one survived after ECMO. Five other subjects could not be completely investigated. During $\mathrm{NO}$ administration, $\mathrm{NO}_{2}$ concentration remained $<1 \mathrm{ppm}$ except for two short trials at $80 \mathrm{ppm}$, when it reached $1.8 \mathrm{ppm}$. No adverse effects related to NO inhalation were observed.

\section{Discussion}

In recent years inhaled NO has gained increasing credit as an effective and safe therapeutic option in newborns with acute respiratory failure [3,10-13]. In particular, two large controlled multicentre trials have recently demonstrated that NO therapy improves systemic oxygenation and may reduce the need for more invasive treatments in these patients, even if, in both studies, the mortality rate observed by the authors was similar in the treated and controlled groups $[14,15]$. However, the reason why some patients show a seldom or unsustained response to NO therapy remains unclear. Furthermore, whether or not an early oxygenation response to NO is associated with a better outcome in these patients remains to be elucidated. The present study has shown that inhalation of NO may result in a marked amelioration of oxygenation in term and near-term newborns with severe hypoxaemic respiratory failure and may reduce the need for ECMO. Although the pattern of response to NO inhalation was variable, it appeared to be correlated with outcome. In fact, patients who showed a rapid and sustained improvement of oxygenation during NO treatment were successfully treated with conventional mechanical ventilation. Conversely, a poor oxygenation response within the first hours of NO inhalation was associated with death or treatment with ECMO. Reversal of a right-to-left shunting at the ductal and/or foramen ovale level during NO was also significantly associated with a good outcome.

The heterogeneous response to NO observed in patients in the present study is consistent with the findings of other studies [13, 16-18]. Such variable oxygenation responses seem to be partially related to the underlying specific disease, although in almost all the pathological conditions associated with PPHN, such as CDH, MAS, RDS or sepsis, both a good and rare response to NO have been observed in different studies [13, 16-18]. For instance, patients with hypoplastic lungs, who may have anatomical and functional pulmonary vascular abnormalities which potentially interfere with the response to $\mathrm{NO}$, were treated 
successfully with NO inhalation in some studies [12-13, 17], while hypoxaemic newborns with hypoplastic lungs and pulmonary hypertension did not improve their oxygenation when inhaled NO was given prior to ECMO [19]. In the present study, five out of six patients with hypoplastic lungs due to $\mathrm{CDH}$ did not improve with $\mathrm{NO}$ and all six eventually died. Furthermore, in a recent multicentre controlled study, inhalation of NO was not beneficial in a group of 25 infants with $\mathrm{CDH}$ unresponsive to aggressive conventional treatment [20]. Thus, the diagnosis of CDH by itself may be predictive of a more severe prognosis. In the remaining patients, except for the subgroup of three infants with RDS who improved with NO and survived, the response to $\mathrm{NO}$ was variable in each diagnostic category.

In a group of newborns with respiratory failure and pulmonary hypertension, DAY et al. [18] recently noticed that patients with normal lung fields or focal disease had a significantly greater improvement of oxygenation than patients with moderate or severe diffuse lung disease. It has been hypothesized that, different ventilatory strategies might be involved in the variable response to $\mathrm{NO}$ and in fact some authors have observed a better oxygenation with the combined use of HFOV and NO compared with either treatment alone [12]. By providing a more effective alveolar recruitment $[21,22]$, HFOV could in fact favour a better delivery of inhaled NO to the pulmonary microcirculation, with enhanced effects on pulmonary pressure and ventilation-perfusion matching. Nevertheless, in three patients with $\mathrm{CDH}$ treated with NO and HFOV no sustained response to NO inhalation was observed.

In addition to the underlying specific disease, the variable effectiveness of NO observed in hypoxaemic newborns is probably influenced by other multiple factors, such as, for instance, the presence of pulmonary hypertension and right-to-left shunting. In early reports, all infants had severe PPHN and the majority of them showed a dramatic response to NO inhalation [10-12]. In a recent study, 11 out of 13 infants with signs of PPHN responded to NO, versus only three out of 10 infants without PPHN [13]. In the present series, presence of PPHN and reversal of shunting during NO treatment was significantly associated with a good outcome. Yet, as suggested by a recent echocardiographic investigation [23], in some patients oxygenation may be enhanced during NO even without pulmonary hypertension and extra-pulmonary shunting, which may relate to the independent effect of NO on ventilation/perfusion matching optimization [24, 25].

In a preliminary report, TURBOW et al. [26] observed a variable response time during NO treatment in 12 newborns with PPHN, which ranged $30 \mathrm{~min}$ to $12 \mathrm{~h}$ from the NO onset.

In the present study, all eight newborns who were successfully treated with NO had a marked improvement of oxygenation from $1 \mathrm{~h}$ of treatment, which was sustained at 6 and $24 \mathrm{~h}$, versus only one out of 12 infants who eventually underwent ECMO or died. This data confirms Salt Lake City's experience [18], where the authors found that $87 \%$ of the patients who showed acutely improved oxygenation during NO inhalation, lowering the OI values $<40$, continued to improve and did well, while only $10 \%$ of patients who did not respond acutely to NO showed an improvement while receiving prolonged therapy. Conversely, in a recent study performed in 25 infants with PPHN,
GOLDMAN et al. [17] observed that an early response to NO did not guarantee either a subsequent sustained effect or the avoidance of ECMO. In fact, 22 out of 25 patients who showed a good initial response, 12 recovered with $\mathrm{NO}$, five survived after ECMO and five died, one despite ECMO.

Another important issue is the differences in inclusion and exclusion criteria chosen in different clinical trials with inhaled NO [27]. Early studies enrolled neonates with severe PPHN who fulfilled ECMO parameters [10 12]. More recently, FINER et al. [13] chose an OI >20, regardless of the presence or absence of PPHN, and the same group adopted an OI $>19$ associated with a mean airway pressure (MAP) $>14 \mathrm{cmH}_{2} \mathrm{O}$ in a selected series of eight premature infants [28]. In other studies, enrolment criteria included a variety of oxygenation and haemodynamic parameters that may have implicated different clinical conditions and patient populations [16-18, 23, 26, $29]$. Thus, as far as the response to NO inhalation is concerned, such various experiences may be scarcely comparable. In the present study, although an OI $>25$ was chosen as the entry criterion, all but five infants had an OI $>40$ before inhalation was commenced (median OI of the whole group was 83.7) and this was mainly due to a rapid progression of the underlying pathological process. Interestingly, initial OI was not different between patients who responded to NO and infants who showed a scarce response and were treated with ECMO or died. Yet, the age at NO onset was greater in the group of patients who did well (45 h in group A versus $19.5 \mathrm{~h}$ in group B), and this may have implicated a more rapid deterioration in the group of infants with worse outcome. Although such difference did not reach statistical significance, this was presumably due to the small number of subjects. Some authors have proposed to use NO in an earlier phase of the disease in order to limit further iatrogenic damage to the lung [30]. However, the risk-benefit ratio of an earlier use of inhaled NO has not yet been clarified, and concerns have been raised as to the potential toxicity of NO in the neonatal [31]. In the patients in the present study no apparent adverse effect possibly related to NO therapy was observed. Yet, information on the potential toxic effects of NO therapy are still rather limited and further controlled studies as well as long-term follow-up evaluations are needed.

In conclusion, the study suggests that inhaled nitric oxide may ameliorate the systemic oxygenation in newborns with severe respiratory failure. Although the small number of patients and the lack of a control group do not allow a complete evaluation of the role of nitric oxide therapy, it is speculated that an improvement of oxygenation may be associated with a good outcome in this group of patients. Neonates who respond to nitric oxide treatment within 1-6 h will have a greater chance to be successfully managed with inhaled nitric oxide. Conversely, patients who show scarce or no response to nitric oxide therapy will probably need extracorporeal membrane oxygenation or die. The variability of clinical responses to nitric oxide appears to be partially related to the underlying specific disease, and infants with hypoplastic lungs seem to be less responsive to such therapy. Presence and reversal of right-to-left shunting and other factors, such as different ventilatory strategies, may also affect the individual response to nitric oxide. A better understanding 
of the time-response patterns to nitric oxide in hypoxaemic newborns with different underlying conditions would be helpful in the early recognition of nonresponder patients, addressing in a timely manner towards combined or alternative treatments.

\section{References}

1. Weigel TJ, Hageman JR. National survey of diagnosis and management of persistent pulmonary hypertension of the newborn. J Perinatol 1990; 10: 369-375.

2. Dworetz AR, Moya FR, Sabo B, Gladstone I, Gross I. Survival of infants with persistent pulmonary hypertension without extracorporeal membrane oxygenation. Pediatrics 1989; 84: 1-6.

3. Morin FC III, Stenmark KR. Persistent pulmonary hypertension of the newborn. Am J Respir Crit Care Med 1995; 151: 2010-2032.

4. Bindl L, Fahnenstich H, Peukert U. Aerosolised prostacyclin for pulmonary hypertension in neonates. Arch Dis Child 1994; 71: F214-216.

5. Wu TJ, Teng RJ, Tsou KI. Persistent pulmonary hypertension of the newborn treated with magnesium sulfate in premature neonates. Pediatrics 1995; 96: 472-474.

6. Hirschl RB, Pranikoff T, Gauger P, Schreiner RJ, Dechert $\mathrm{R}$, Bartlett RH. Liquid ventilation in adults, children, and full-term neonates. Lancet 1995; 346: 1201-1202.

7. Bartlett RH, Roloff DW, Cornell RG, et al. Extracorporeal circulation in neonatal respiratory failure: a prospective randomized study. Pediatrics 1985; 76: 479-487.

8. Stolar CJ, Snedecor SM, Bartlett RH. Extracorporeal membrane oxygenation and neonatal respiratory failure: experience from the extracorporeal life support organization. J Pediatr Surg 1991; 26: 563-571.

9. Field $\mathrm{J}$ and the UK Collaborative ECMO Trial Group. UK collaborative randomised trial of neonatal extracorporeal membrane oxygenation. Lancet 1996; 348: 75-82.

10. Roberts JD, Polaner DM, Lang P, Zapol WM. Inhaled nitric oxide in persistent pulmonary hypertension of the newborn. Lancet 1992; 340: 818-819.

11. Kinsella JP, Neish SR, Shaffer E, Abman SH. Low-dose inhalational nitric oxide in persistent pulmonary hypertension of the newborn. Lancet 1992; 340: 819-820.

12. Kinsella JP, Neish SR, Ivy DD, Shaffer E, Abman SH. Clinical responses to prolonged treatment of persistent pulmonary hypertension of the newborn with low doses of inhaled nitric oxide. J Pediatr 1993; 123: 103-108.

13. Finer NN, Etches PC, Kamstra B, Tierney AJ, Peliowski A, Ryan CA. Inhaled nitrio oxide in infants referred for extracorporeal membrane oxygenation: dose response. $J$ Pediatr 1994; 124: 302-308.

14. Bührer C, Merker G, Falke K, Versmold H, Obladen M. Dose-response to inhaled nitric oxide in acute hypoxemic respiratory failure of newborn infants: a preliminary report. Pediatr Pulmonol 1995; 19: 291-298.

15. The Neonatal Inhaled Nitric Oxide Study Group. Inhaled nitric oxide in full-term and nearly full-term infants with hypoxic respiratory failure. $N$ Engl J Med 1997; 336: 597-604.

16. Roberts JD, Fineman JR, Morin FC III, et al. Inhaled nitric oxide and persistent pulmonary hypertension of the newborn. N Engl J Med 1997; 336: 605-610.

17. Goldman AP, Tasker RC, Haworth SG, Sigston PE, Macrae DJ. Four patterns of response to inhaled nitric oxide for persistent pulmonary hypertension of the newborn. Pediatrics 1996; 98: 706-713.

18. Day RW, Lynch JM, White KS, Ward RM. Acute response to inhaled nitric oxide in newborns with respiratory fai-lure and pulmonary hypertension. Pediatrics 1996; 98: 698-705.

19. Karamanoukian HL, Glick PL, Zayek M, et al. Inhaled nitric oxide in congenital hypoplasia of the lungs due to diaphragmatic hernia or oligohydramnios. Pediatrics 1994; 94: 715-718.

20. The Neonatal Inhaled Nitric Oxide Study Group. Inhaled nitric oxide and hypoxic respiratory failure in infants with congenital diaphragmatic hernia. Pediatrics 1997; 99: 838845.

21. Clark RH, Yoder BA, Sell MS. Prospective, randomized comparison of high-frequency oscillation and conventional ventilation in candidates for extracorporeal membrane oxygenation. J Pediatr 1994; 124: 447-454.

22. Clark RH. High-frequency ventilation. J Pediatr 1994; 124: 661-670.

23. Roze JC, Storme L, Zupa V, Morville P, Dinh-Xuan AT, Mercier JC. Echocardiographic investigation of inhaled nitric oxide in newborn babies with severe hypoxaemia. Lancet 1994; 344: 303-305.

24. Abman SH, Kinsella JP, Schaffer MS, Wilkening RB. Inhaled nitric oxide therapy in a premature newborn with severe respiratory distress and pulmonary hypertension. Pediatrics 1993; 92: 606-609.

25. Rossaint R, Kalke KJ, López F, Slama K, Pison U, Zapol WM. Inhaled nitric oxide for the adult respiratory distress syndrome. N Engl J Med 1993; 328: 399-405.

26. Turbow R, Waffarn F, Yang L, Sills J, Hallman M. Variable oxygenation response to inhaled nitric oxide in severe persistent pulmonary hypertension of the newborn. Acta Paediatr 1995; 84: 1305-1308.

27. Stark AR, Davidson D. Inhaled nitric oxide for persistent pulmonary hypertension of the newborn: implications and strategy for future "high-tech" neonatal clinical trials. Pediatrics 1995; 96: 1147-1151.

28. Peliowski A, Finer NN, Etches PC, Tierney AJ, Ryan CA. Inhaled nitric oxide for premature infants after prolonged rupture of the membranes. J Pediatr 1995; 126 : 450-453.

29. Stranak Z, Zabrodsky V, Simak J. Changes in alveolararterial oxygen difference and oxygenation index during low-dose nitric oxide inhalation in 15 newborns with severe respiratory insufficiency. Eur J Pediatr 1996; 155: 907-910.

30. Lönnqvist PA, Winberg P, Lundell B, Sellden H, Olsson GL. Inhaled nitric oxide in neonates and children with pulmonary hypertension. Acta Paediatr 1994; 83: 11321136.

31. Abman SH, Kinsella JP. Inhaled nitric oxide therapy of pulmonary hypertension and respiratory failure in premature and term neonates. Adv Pharmacol 1995; 34: 457474. 